\title{
New Approaches in Breast Cancer Therapy Through Green Nanotechnology and Nano-Ayurvedic Medicine - Pre-Clinical and Pilot Human Clinical
} Investigations

This article was published in the following Dove Press journal:

International Journal of Nanomedicine

Menka Khoobchandani, ${ }^{1,2}$ Kavita K Katti, ${ }^{1,2}$ Alice Raphael Karikachery, ${ }^{1,2}$

Velaphi C Thipe, (ID ${ }^{1,2}$ Deepak Srisrimal, ${ }^{3}$

Darsha Kumar

Dhurvas Mohandoss, ${ }^{3}$

Rashmi Dhurvas Darshakumar, ${ }^{3}$

Chintamani M Joshi, ${ }^{3}$ Kattesh V Katti ${ }^{1,2,4}$

'Department of Radiology, University of Missouri, Columbia, MO 652I2, USA; ${ }^{2}$ Institute

of Green Nanotechnology, University of

Missouri, Columbia, MO 652I2, USA;

${ }^{3}$ Dhanvantari Nano Ayushadi Pvt Ltd, Chennai 600017, India; ${ }^{4}$ Department of Physics,

Department of Pharmacology, Department of Biological Engineering, University of Missouri

Research Reactor (MURR), University of

Missouri, Columbia, MO 65212, USA

\section{Video abstract}

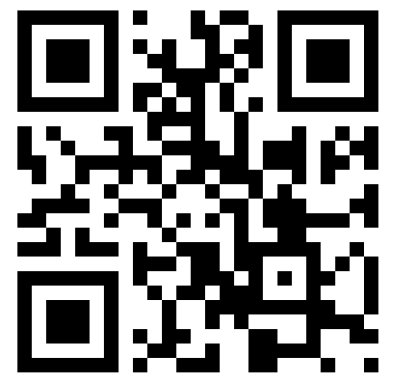

Point your SmartPhone at the code above. If you have a QR code reader the video abstract will appear. Or use: https://youtu.be//Xbvpc4CANA

Correspondence: Kattesh V Katti Department of Radiology, University of Missouri, One Hospital Drive, Columbia, MO 65212 USA

Tel +I 573 882-5656

Email KattiK@health.missouri.edu
Purpose: The overarching objective of this investigation was to investigate the intervention of green nanotechnology to transform the ancient holistic Ayurvedic medicine scientifically credible through reproducible formulations and rigorous pre-clinical/clinical evaluations.

Methods: We provide, herein, full details: (i) on the discovery and full characterization of gold nanoparticles-based Nano Swarna Bhasma (henceforth referred to as NSB drug); (ii) In vitro anti-tumor properties of NSB drug in breast tumor cells; (iii) pre-clinical therapeutic efficacy studies of NSB drug in breast tumor bearing SCID mice through oral delivery protocols and (iv) first results of clinical translation, from mice to human breast cancer patients, through pilot human clinical trials, conducted according to the Ayurveda, Yoga and Naturopathy, Unani, Siddha and Homoeopathy (abbreviated as AYUSH) regulatory guidelines of the Government of India in metastatic breast cancer patients.

Results: The preclinical in vitro and in vivo investigations, in breast tumor bearing mice, established unequivocally that the NSB Nano-Ayurvedic medicine-gold nanoparticles-based drug is highly effective in controlling the growth of breast tumors in a dose dependent fashion in vivo. These encouraging pre-clinical results prompted us to seek permission from the Indian Government's holistic medicine approval authority, AYUSH, for conducting clinical trials in human patients. Patients treated with the NSB drug capsules along with the "standard of care treatment" (Arm B) exhibited 100\% clinical benefits when compared to patients in the treatment Arm A, thus indicating the tremendous clinical benefits of NSB drug in adjuvant therapy.

Conclusion: We have succeeded in clinically translating, from mice to humans, in using proprietary combinations of gold nanoparticles and phytochemicals to develop the NanoAyurvedic drug: Nano Swarna Bhasma (NSB), through innovative green nanotechnology, for treating human metastatic breast cancer patients.

Keywords: gold nanoparticles, mangiferin, mango peel, Nano Swarna Bhasma, NSB, triple negative breast tumor, pilot clinical

\section{Introduction}

The traditional Indian holistic medicine (Ayurveda), with over 5000 years of rich history, is gaining considerable acceptance in recent years because plant-based preparations, which play a major role in the Ayurvedic healing processes, have shown reliable curative effects in many chronic conditions. ${ }^{1-10}$ Approximately two-thirds populations of the developed and developing countries have reported 
using one or the other form of alternative or complementary medicine. ${ }^{11-15}$ Extensive literature on Ayurvedic medicine supports claims of significant improvement in patients' symptoms thereby enhancing their quality of life. ${ }^{16-18}$ Despite the long history of Ayurvedic medical modality, rigorously tested and scientifically reproducible formulations of Ayurvedic-relevant polyherbal drugs for the treatment of various diseases and disorders remain largely unestablished. The lack of reproducible Ayurvedic formulations have also impeded the development of reliable clinical trials data from human patient populations. Overall, a myriad of scientific reasons have contributed to significantly limited acceptability of Ayurvedic medicine within the global patient population. As part of our continued quest to develop scientific rationale for Ayurvedic medicine, we have been researching, for over two decades, on the application of green nanotechnology to develop universally acceptable Ayurvedic formulations. ${ }^{19-26}$ Green nanotechnology allows the production and efficient encapsulation of Ayurvedic-relevant phytochemicals on gold nanoparticles. Our long-standing scientific efforts, with a focus on gold nanoparticles, are based on the rationale that in Ayurvedic medicine, gold metal is ubiquitously used in combination with phytochemicals from various herbs including cinnamon, clove, gooseberry, grape, mango, turmeric and a host of herbs. ${ }^{19-26}$ Our efforts, serendipitously, led to a series of discoveries confirming that the phytochemicals used in Ayurvedic medicines are indeed electron-rich antioxidants and that the interaction of gold metallic precursors with phytochemically-harnessed electrons produced herb/ phytochemicals-encapsulated, well-defined, gold nanoparticles. The large surface area of gold nanoparticles embedded with atomically active nano surface motif allowed highly efficient encapsulation of phytochemical(s) - thus paving, for the first time, an innovative green nanotechnology route providing reproducible and scientifically verifiable Nano-Ayurvedic formulations. ${ }^{19-24,26-49}$

Choice of gold nanoparticles is further necessitated by the fact that this metal embodies the iconic Ayurvedic medication "Swarna Bhasma" (SB) ("Swarna" meaning gold, "Bhasma" meaning ash) which contains gold particles along with various herbal mixtures. Swarna Bhasma is an ancient Indian medicine with established anticancer activity ${ }^{50,51}$ Extensive studies have reported on the uncharacterized chemical features of SB thus making it difficult for clinical acceptance and penetration of this Ayurvedic drug within the larger patient populations across the world. ${ }^{52,53}$ In order to circumvent this long-standing problem, we have developed an innovative green nanotechnology approach for the production of gold nanoparticles (AuNPs) employing complete scientific control on its formulation for reproducible large-scale production as shown in Figures 1 and 2. Our overarching rationale was to develop reproducible formulations of Swarna Bhasma, through green nanotechnology, using various phytochemicals adhering to strict Ayurvedic principles. We have coined a new term referred to as "Nano-Ayurvedic Medicine" in order to capitalize on the important role of nanotechnology in making Ayurvedic medicine more effective. The term "Nano-Ayurvedic medicine" has been recently approved by the US Patents and Trade Marks office. ${ }^{54}$ We have succeeded in using proprietary combinations of gold nanoparticles and phytochemicals from mango, turmeric, gooseberry and gum arabic to develop Nano Swarna Bhasma through green nanotechnology. In this report, we provide full details: (i) on the discovery and full characterization of gold nanoparticles-based Nano Swarna Bhasma (NSB drug); (ii) Drug loading concepts to prove that the gold nanoparticles produced through cocktails of phytochemicals from mango peel contain predominantly the mangiferin functionalized gold nanoparticles; (iii) In vitro anti-tumor properties of NSB drug; (iv) pre-clinical therapeutic efficacy of NSB drug in breast tumor bearing SCID mice through oral delivery protocols and (v) first results of pilot human clinical trials, conducted according to the AYUSH regulatory guidelines in metastatic breast cancer patients. The primary objective of this pilot clinical trials investigation was to assess the safety profile, and to determine the number of patients who experience adverse events by NCI toxicity criteria at every course. The secondary objective was to determine the efficacy of NSB drug (Trade name: DNANOSTANNA) in terms of response rate in participating breast cancer patients assessed by radiographic evaluation by RECIST Criteria. Our overall assessments included evaluating the quality of life of patients who participated in this study. The overall oncological implications of green nanotechnology-based Ayurvedic drugs are discussed.

\section{Materials and Methods Preclinical Studies Materials}

Gold salt, and MTT assay kit (3-(4,5-dimethylthiazol-2-yl)2,5-diphenyltetrazolium bromide) were obtained from Sigma 


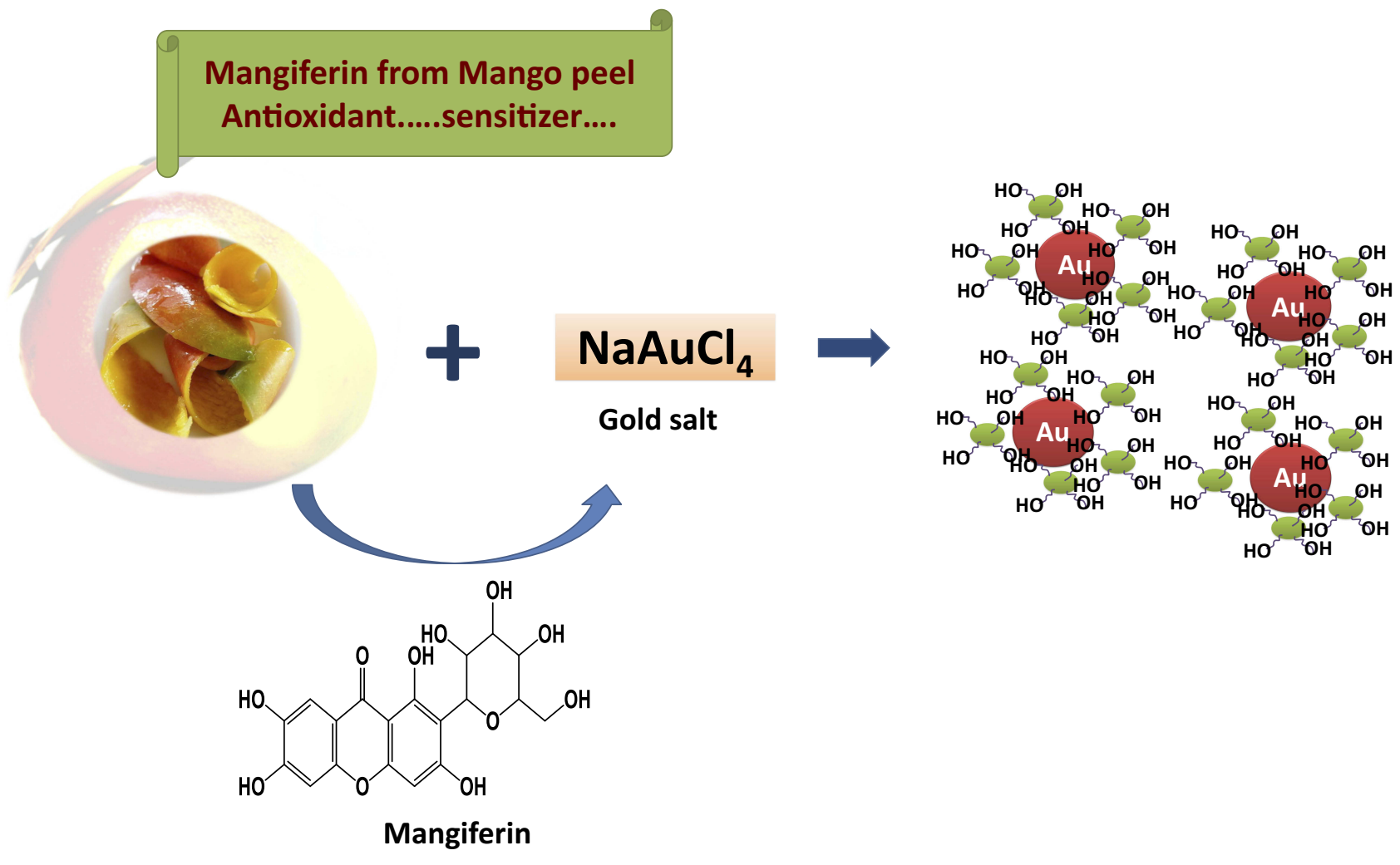

Figure I Production of therapeutic MP-AuNPs through Green Nanotechnology.

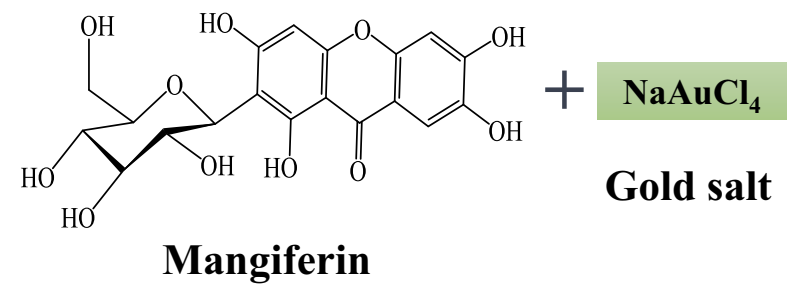

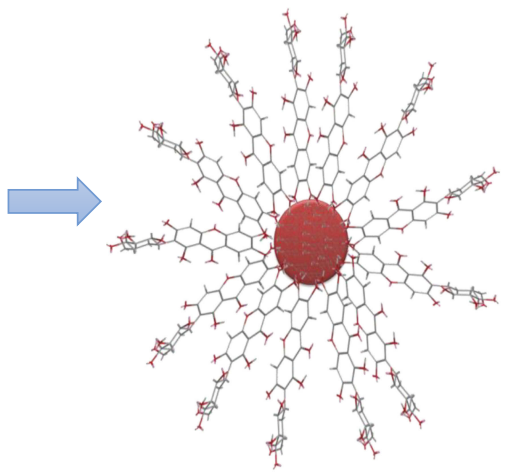

MGF-AuNPs

Figure 2 Production of therapeutic MGF-AuNPs through Green Nanotechnology.

(St. Louis, MO, USA). RPMI, fetal calf serum, TryplE, Trypan blue and DAPI (4',6-diamidino-2-phenylindole) were obtained from Thermo Fisher Scientific, USA. Double distilled water was used throughout the experiment. Mangiferin was purchased as a $99 \%$ pure phytochemical from Sigma Aldrich and used without further purification.

\section{Cell Line}

The MDA-MB-231 (breast tumor cells from human breast tumor origin) and HAECs (human aortic endothelial) cell lines were obtained from the American Type Culture Collection (ATCC; Manassas, VA), and cultured by the University of Missouri Cell and Immunobiology Core facility using procedures recommended by ATCC.

\section{Characterization of Nano Swarna Bhasma (NSB) Drug}

Transmission electron microscope (TEM; JEOL 1400, LTE, Tokyo, Japan), Scanning Transmission electron microscope (STEM) and Electron Energy Loss Spectroscopy (EELS) 
images were used to characterize various gold nanoparticles. Zeta potential was obtained by Zetasizer Nano S90 (Malvern Instruments Ltd. USA) to evaluate the overall in vitro stability of nanoparticles against agglomeration.

\section{NSB Drug Formulation}

The main nanoparticulate drug in our formulation is derived from gold nanoparticles produced through the interaction of phytochemicals in mango peel with gold salt as discussed below:

\section{Preparation of Mango Peel Powder}

Mango (Mangifera indica) peel purchased from a reliable herbal source from India was used in all the experiments. Mango peel was washed with doubly ionized water to remove any contaminants or dust particles and incubated at $50^{\circ} \mathrm{C}$ for $4 \mathrm{hr}$ and then grinded to obtain dry powder. Mango peel powder was stored at room temperature and used for subsequent gold nanoparticles synthesis.

Synthesis of Mango Peel Phytochemicals Coated Gold Nanoparticles (MP-AuNPs)

After extensive experimentation, we arrived at the following reproducible ratios of mango peel powder with respect to gold salt concentrations. Thirty milligrams of the dry mango peel powder was added to $6 \mathrm{~mL}$ of DI water in a $20 \mathrm{~mL}$ vial and stirred for $10 \mathrm{~min}$ at $\mathrm{rt}$ for the complete homogenous suspension. Then, $100 \mu \mathrm{L}$ of $0.1 \mathrm{M} \mathrm{NaAuCl}_{4}$ solution was added and the color of the solution turned to ruby-red within $2 \mathrm{~min}$, indicating the formation of gold nanoparticles. The solution was filtered to remove the remaining insoluble mango peel powder and used for full characterizations as outlined below.

Synthesis of Mangiferin (Major Phytochemical in Mango Peel) Conjugated Gold Nanoparticles (MGF-AuNPs)

After extensive experimentation, we arrived at the following reproducible ratios of mangiferin with respect to gold salt concentrations. The mangiferin gold nanoparticles were produced by mixing $4.2 \mathrm{mg}$ of mangiferin (MGF) in $6 \mathrm{~mL}$ of doubly deionized (DI) water. The solution was stirred at $100^{\circ} \mathrm{C}$ for $10 \mathrm{~min}$ to dissolve all the MGF in water to get a clear solution. Gold salt $(100 \mu \mathrm{L}$ of $0.1 \mathrm{M})$ was added to the reaction mixture when a ruby-red coloration was observed within a few seconds of addition. The reaction mixture was further stirred for an additional 2 hrs to make sure that all the gold was transformed to the corresponding mangiferin functionalized gold nanoparticles (MGF-AuNPs). Finally, the
AuNPs were centrifuged twice in $2 \mathrm{~mL}$ eppendorf tubes at $12,000 \mathrm{rpm}$ at $12^{\circ} \mathrm{C}$ for $15 \mathrm{~min}$ to remove any unreacted MGF or gold salt.

Gold nanoparticles obtained through mango peel extracts (MP-AuNPs) as well as those produced through the interaction with mangiferin (MGF-AuNPs) were characterized by UV-Visible absorption spectrophotometry, particle size analyzer, and transmission electron microscopy (TEM). The amount of $\mathrm{Au}$ was calculated by atomic absorption spectrometry (AAS) technique. Nanoparticles were stored at $4^{\circ} \mathrm{C}$ for further use in biological evaluations.

In order to adhere with the Indian traditional medicine Ayurveda modality, we introduced proprietary combinations of additional plant phytochemicals from Amalaki (Emblica officinalis), Amra (Mangifera indica), Haridra (Curcumin longa), Babbula (Acacia nilotica), Yashtimadhu (Glycyrrhiza glabra) with MP-AuNPs (Scheme 1). Overall, we call this combination of MP-AuNPs with the proprietary phytochemical excipients as Nano Swarna Bhasma drug with the trade name as DNANOSTANNA. NSB's formulation uses unique green nanotechnology without the use of any toxic organic chemicals or solvents. All formulations are reproducible. NSB was subjected to extensive in vitro and in vivo investigations using triple-negative breast tumor cells. The anti-tumor assays are described below.

\section{Cell Viability Assay}

The effect of NSB drug on breast cancer (MDA-MB-231) and normal (HAECs) cells, viability was determined using MTT assay. The intensity of developed color was measured by micro plate reader (Molecular device, USA) operating at $570 \mathrm{~nm}$ wavelength. ${ }^{55}$ Percent cell viability was calculated by using the formula: $(\mathrm{T} / \mathrm{C}) \times 100$, where $\mathrm{C}=$ Absorbance of control, $\mathrm{T}=$ Absorbance of treatment. The IC-50 values were calculated using the Origin software.

\section{Animal Studies}

All experiments involving animals were approved by the Institutional Animal Care and Use Committees (IACUC) of the Harry S. Truman Memorial Veterans Hospital and the University of Missouri, and were performed according to the Guidelines for the Care and Use of Laboratory Animals. Imprinting control regions-severe combined immunodeficient (ICR-SCID) female mice (from Taconic Farms, Hudson, New York) were used for the therapeutic study. The mice used in our investigations weighed 24-30 g. 


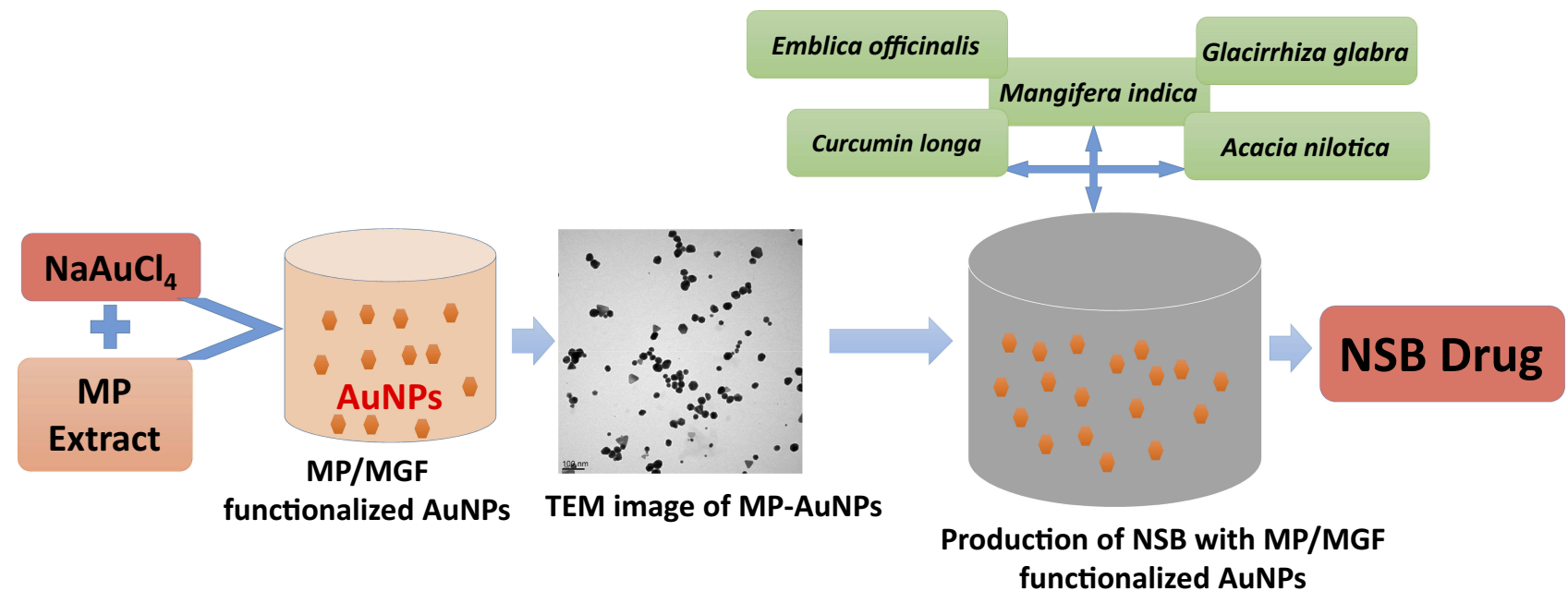

Scheme I Gold nanoparticle phytochemicals incorporated 'Nano Swarna Bhasma' (NSB) formulation using proprietary amounts of phytochemicals from Amalaki (Emblica officinalis), Amra (Mangifera indica), Haridra (Curcumin longa), Babbula (Acacia nilotica), and Yashtimadhu (Glycyrrhiza glabra).

The SCID female mice were subcutaneously inoculated with $10 \times 10^{6}$ MDA-MB-231 cells (suspended in $0.1 \mathrm{~mL}$ of sterile DPBS (Dulbecco's phosphate-buffered saline) and Matrigel $\left.^{\circledR}(2: 1, \mathrm{v}: \mathrm{v})\right)$ in the right hind flank under inhalation anesthesia (isoflurane/oxygen). After inoculation, tumors were allowed to grow for 3 weeks, during this time tumors were measured by digital caliper measurements and calculated as length $\mathrm{x}$ width $\mathrm{x}$ height. The mice were randomly divided into three groups ( $\mathrm{n}=7 /$ group) with no significant difference in tumor volume, the day of randomization was considered as day zero of the therapy study. On day zero, mice were treated orally with drug mixed in peanut butter as follows:

- Group 1- Untreated control (peanut butter)

- Group 2- NSB drug treated (3 mg drug/30 gm mouse);

- Group 3- NSB drug treated (7 mg drug/30 gm mouse);

Animals were treated orally twice per week until the end of the study. The animals were monitored for their tumor volume, body weight and overall health condition during the study period. At the end of the study, animals were sacrificed.

A separate group $(n=7)$ was kept as a control group (no tumor and no treatment). This group of animals served as a control group for body weight measurements. Animals were sacrificed at the end of the study.

\section{Statistical Analysis}

All experimental data for pre-clinical study were given as mean \pm SEM. Statistical analysis was carried out using the one-way analysis of variances (ANOVA) using Graph Pad Prism software. $P<0.05$ was considered significant.

\section{Pilot Clinical Trial Investigations}

After obtaining highly encouraging in vitro antitumor assays and in vivo therapeutic efficacy studies in breast tumor bearing mice, we obtained regulatory permission from the Indian government regulatory authority of AYUSH (DNA_SPN_B001_17) for initiating a pilot clinical trial investigation in breast cancer patients. The details of clinical trials planning, inclusion/exclusion criteria, dosage, endpoint and overall clinical efficacy results are summarized in the following sections:

Here we describe the overall methodology of our study aimed at evaluating the safety and efficacy of NSB drug (herbal formulation) as a treatment for breast cancer. The study followed a randomized, multicenter, parallel design in female patients with pathologically confirmed invasive breast carcinoma stage IIIA or IIIB. At visit 1, after the study personnel explained the study procedures, written informed consent was obtained in the presence of the investigator from patients who were willing to participate in the study. Each patient, then underwent screening procedures. Screening procedures included medical history, clinical examination and laboratory investigations (hematology, biochemistry, urinalysis and serology). Urine pregnancy test was not performed as none of the enrolled female patients were of child bearing age. Patient's electrocardiogram (ECG) and $\mathrm{X}$-ray were taken at the time of screening.

Each patient was screened for the presence of Breast Carcinoma Stage IIIA or IIIB by computed tomography (CT) scan (RECIST criteria) before enrolling into the study. Upon satisfying the inclusion and exclusion criteria as per protocol, patients were enrolled in the study. 


\section{Inclusion and Exclusion Criteria}

Inclusion Criteria: Participants Who Met the Following Criteria Were Included in This Study

- Female patients between age 18 to 65 years of age with pathologically confirmed invasive breast carcinoma stage IIIA or IIIB

- HER-2/Neu negative status or HER-2/Neu positive status.

- Bi-dimensionally measurable and evaluable disease lesion.

- No evidence of disease outside the breast or chest wall, except for ipsilateral axillary lymph nodes

- Subject willing to participate by providing written informed consent

- Life expectancy must be $\geq 6$ months

- Eastern Cooperative Oncology Group (ECOG) performance status with 0 or 1

- Chest CT scan without evidence of metastasis at the time of screening

Laboratory value criteria was as follows:

- White Blood Cells $\geq 3000 / \mathrm{mm}^{3}$

- Neutrophils $\geq 2000 / \mathrm{mm}^{3}$

- Hemoglobin $\geq 8 \mathrm{~g} / \mathrm{dL}$

- Platelets $\geq 100,000 / \mathrm{mm}^{3}$

- Serum creatinine $\leq 1.5 \times$ Upper normal limit (UNL)

- Alkaline phosphatase $\leq 1.5 \times \mathrm{UNL}$

- Total serum bilirubin $\leq 1.5 \times \mathrm{UNL}$ for the institution.

- Serum Glutamic-Oxaloacetic Transaminase (SGOT) $\leq 1.5 \times \mathrm{UNL}$

- Serum calcium $\leq \mathrm{UNL}$

- Pregnancy test must be negative.

Additional criteria included that subjects with child bearing potential must be willing to agree to use effective contraceptive methods while on treatment and for 3 months after the completion of study.

\section{Exclusion Criteria}

- Prior systemic treatment for breast cancer with hormonal therapy, chemotherapy, or any other anticancer therapy.

- Prior radiation therapy.

- Participants who received or receiving or scheduled to receive post-operative radiotherapy.

- History of a malignancy other than breast cancer
- Participants taking alternative therapies for cancer must stop taking these therapies prior to randomization. Alternative therapies were not allowed during the treatment or follow-up portions of the study.

- Peripheral neuropathy $\geq$ Grade 2 .

- ECG with significant abnormalities (as determined by the investigator)

- Participants who are medically unstable, including but not limited to active infection, acute hepatitis, gastrointestinal bleeding, uncontrolled cardiac arrhythmias, interstitial lung disease, inflammatory bowel disease, uncontrolled angina, uncontrolled hypercalcemia, uncompensated congestive heart failure, uncontrolled diabetes, dementia, seizures, superior vena cava syndrome.

Our pilot clinical trials were based on a comparative study model with two arms. As per plan, a total of six patients enrolled in the study were randomized to either of the two treatment arms: Treatment A and Treatment B in $1: 1$ ratio. As per the sponsor's requirement, one additional patient was enrolled later in the study to replace one withdrawn patient from treatment arm B. Details of treatment $\operatorname{arm} \mathrm{A}$ and B are outlined in the following sections-

All the eligible patients were informed by the site coordinator to visit the site for randomization within 14 days ( \pm 7 days) of screening (visit 2) for baseline evaluations. After randomization and all baseline measurements, all eligible patients received their respective study treatments in the following manner:

Patients in Treatment Arm A Received the Following "Standard of Care Treatment"

Doxorubicin injection, concentration of $60 \mathrm{mg} / \mathrm{m}^{2}$, every 3 weeks as a $1 \mathrm{hr}$ intravenous infusion. In addition, this patient group also received Cyclophosphamide injection, concentration of $600 \mathrm{mg} / \mathrm{m}^{2}$, every 3 weeks as a $1 \mathrm{hr}$ intravenous infusion.

Patients in Treatment Arm B Received the Following Doxorubicin injection, concentration of $60 \mathrm{mg} / \mathrm{m}^{2}$, every 3 weeks as a $1 \mathrm{hr}$ intravenous infusion, Cyclophosphamide injection, concentration of $600 \mathrm{mg} / \mathrm{m}^{2}$, every 3 weeks as a $1 \mathrm{hr}$ intravenous infusion. In addition, this group of patients were administered with the experimental NSB Drug in doses of two capsules thrice a day after food.

These doses for every patient was calculated based on body surface area (BSA). Four such cycles were repeated 
over a period of 12 weeks. Investigator dispensed sufficient quantity of NSB drug and patient diary to each patient was randomized in treatment $\mathrm{B}$ with dosing instructions. In the arm B, patients were instructed to take two NSB drug capsules thrice a day after food with sufficient quantity of water by themselves at home. All patients maintained records of each dosing details in the patient diary. Details of dosing were documented appropriately in chronic renal failure (CRF) through patient's physical examinations which included observation of vital signs. Laboratory investigations, including hematology, clinical chemistry and urinalysis were done (except for two patients $-02-002$ and $02-003$ whose urinalysis was not done for visit 1 and 3, respectively). Serology was performed at visit 1 only and was not performed at all the visits as mentioned in the protocol. Patients were evaluated through quality of life (QoL) questionnaires at every visit except visit 1 . CT scan (RECIST criteria check) was repeated at visit 4 and end of study visit post 12 weeks. Adherence to assigned regimen was assessed by recording the number of capsules dispensed and returned by the patient at each visit. Study drug compliance was checked by counting the quantity of returned/unused investigational products and the review of the patient diaries, which they brought at every visit. Unused amounts were documented in the drug log book. Patient's concomitant medication received was also documented. Adverse events were assessed by NCI toxicity criteria at every course.

\section{Number of Patients Planned and Analyzed}

Six patients were planned; seven eligible patients with stage III A or III B breast cancer were enrolled; six patients completed the clinical investigation. Out of seven patients enrolled into the study, one patient was withdrawn after visit 2 due to non-compliance. Full analysis set (FAS) and per protocol set (PPS) consisted of six patients.

\section{Efficacy and Safety}

As part of efficacy and safety, we defined the following primary and secondary endpoints for our investigation.

\section{Primary Endpoint (Safety)}

NCI toxicity criteria at every course-adverse events were summarized by NCI CTC (Common Toxicity Criteria) grading and tabulated by severity and relationship to the study medications.

\section{Secondary Endpoint (Efficacy; RECIST Criteria)}

Efficacy of the NSB drug in terms of response rate in participating breast cancer patients were assessed by Radiographic Evaluation by RECIST Criteria. Improvement in Quality of life comparing baseline with end of study was also used as a criterion for efficacy.

Statistical Analysis Related to Pilot Clinical Trial Study As per the plan, the data from both the centers that participated in this protocol was used, so that an adequate number of patients were available for analysis. The data were analyzed by 15 Clinical Research Pvt. Ltd - a clinical trials company based in Chennai, India. Efficacy variables were analyzed using data from all patients to whom study treatment was assigned. Following the intent-to-treat principle, patients were analyzed according to the treatment they were assigned at randomization. As per plan, all efficacy variables were analyzed by FAS and PPS. PP population consisted of all those full analyses set subjects and those completed the study without any major protocol deviation. None of the patients showed any major protocol deviation. Comparison between the groups was performed for standard of care treatment alone and standard of care treatment with NSB drug. All categorical variables were summarized in tabular form by means of frequency counts and percentages. All continuous variables were summarized in tabular form by presenting the $\mathrm{n}$, mean, median, standard deviation (SD), minimum, and maximum.

\section{Safety}

Safety population comprised of all randomized patients who received at least one dose of study treatment. Patients were analyzed according to the treatment received. Adverse events, vital signs, hematology, biochemistry parameters were summarized descriptively by treatment groups.

\section{Results for Preclinical Studies Synthesis and Characterization of MP-AuNPs and MGF-AuNPs}

Mangiferin (1,3,6,7-tetrahydroxyxanthone-C2-D glucoside; Figure 1) is a polyphenol functionalized-D-glucoside-xanthone family of phytochemical found in abundance in the Anacardiaceae and Gentianaceae family of plant species especially in mangoes skin and honeybush tea. ${ }^{56,57}$

Mango peel (MP) extracts and mangiferin (MGF), (one of the major phytochemicals in MP), were utilized to produce (MP-AuNPs and MGF-AuNPs) gold nanoparticles. Mango peel cocktails extract-based and MGF 
conjugated gold nanoparticles (AuNPs) were synthesized by redox reactions where electrons from phytochemicals are used to reduce gold salt to the corresponding gold nanoparticles (Figures 1 and 2). The production of MPAuNPs and MGF-AuNPs were confirmed by employing extensive characterization tools. It is important to note that the mangiferin molecule comprises of glucose and xanthonoid (polyphenols) units. Glucose molecule of MGF supports to stabilize nanoparticles and hydroxyl groups of the xanthonoid unit play a significant role as powerful reducing agents to reduce the gold salt to the corresponding gold nanoparticles (MGF-AuNPs).

$\mathrm{UV}$-visible spectrophotometric analysis confirmed the surface plasmon resonance (SPR) of MP-AuNPs and MGFAuNPs at $\sim 535 \mathrm{~nm}$ (Figure 3), thus confirming the successful synthesis of AuNPs. The transmission electron microscopic (TEM) analysis of MP-AuNPs and MGF-AuNPs indicated that these nanoparticles are spherical, mono-disperse and homogenous with the core size of $35 \pm 2 \mathrm{~nm}$ (Figure 3 ). The results obtained by dynamic light scattering instrument revealed that MGF-AuNPs showed a hydrodynamic size at $55 \pm 5 \mathrm{~nm}$ whereas MP-AuNPs exhibited a size of $65 \pm 5 \mathrm{~nm}$. Zeta potential obtained for MGF-AuNPs and MP-AuNPs indicated large negative values of $-40 \pm 2 \mathrm{mV}$ and $-20 \pm 2 \mathrm{mV}$, respectively (Table 1). Our observations of hydrodynamic sizes for both AuNPs which are greater than their core sizes ( $35 \pm 2 \mathrm{~nm})$, confirmed the encapsulation of phytochemicals/ MGF onto the gold nanoparticle. The larger negative zeta potential, observed for MGF-AuNPs and MP-AuNPs, suggested strong repulsive forces between the nanoparticles, thus attributing to optimum in vitro and in vivo stability against agglomeration forces.

\section{Formulation of NSB Drug}

NSB drug was formulated by mixing MP-AuNPs with proprietary combinations of plant phytochemicals from Amalaki (Emblica officinalis), Amra (Mangifera indica), Haridra (Curcumin longa), Babbula (Acacia nilotica), Yashtimadhu (Glycyrrhiza glabra) (Scheme 1). Reproducibility of this formulation has been confirmed at small as well as at industrial scales by measuring all the physicochemical parameters which are discussed in the following sections.

\section{Characterization of NSB Drug}

The NSB drug was characterized by TEM technique for qualitative analysis of AuNPs in the drug formulation. The core size of AuNPs, obtained by TEM, STEM and EELS indicated that the NPs are spherical, mono-disperse and homogenous with the core size of $35 \pm 2 \mathrm{~nm}$ (Figure 4). The solutions of NSB drug were also analyzed for zeta potential $(-17 \pm 5 \mathrm{mV})$ by dynamic light scattering (DLS) instrument.

\section{Drug Loading of Phytochemicals from Mango Peel on Gold Nanoparticles}

Mango peel contains a large abundance of mangiferin ( $42 \%$ of the total polyphenols, Figure 5) - a heat stable and naturally occurring pharmacologically active phytochemical with antiinflammatory, antitumor and antioxidant activities. ${ }^{27,58-60}$ As shown in Figure 5, additional phytochemicals found in mango peel in smaller proportions include quercetin, quercetin 3-o-rhamnoside, Kaempferol, and Rhamnetin. ${ }^{58}$

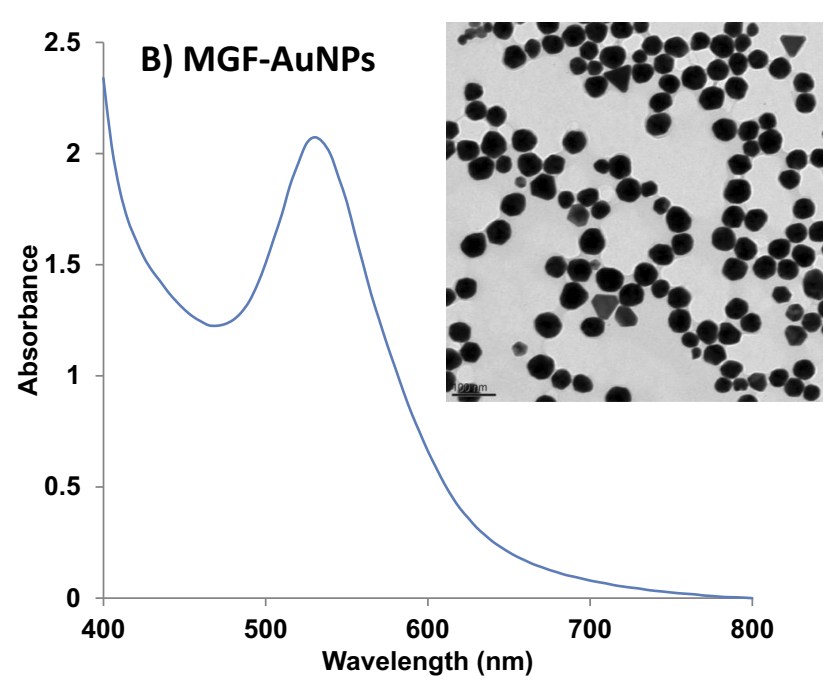

Figure 3 Characterization of AuNPs by UV-Visible spectrum and TEM techniques (A) MP-AuNPs, (B) MGF-AuNPs. 
Table I Physicochemical Data Parameters of Gold Nanoparticles (AuNPs)

\begin{tabular}{|l|l|l|l|l|l|}
\hline Sample & $\begin{array}{l}\text { Absorbance } \\
(\mathbf{n m})\end{array}$ & $\begin{array}{l}\text { Core Size by } \\
\text { TEM }(\mathbf{n m})\end{array}$ & $\begin{array}{l}\text { Hydrodynamic } \\
\text { Size by DLS (nm) }\end{array}$ & $\begin{array}{l}\text { Zeta Potential } \\
(\mathbf{m V})\end{array}$ & $\begin{array}{l}\text { [Au] in AuNPs } \\
\text { (by AAS, ppm) }\end{array}$ \\
\hline MGF-AuNPs & 535 & $35 \pm 2$ & $55 \pm 5$ & $-40 \pm 2$ & 327 \\
MP-AuNPs & 535 & $35 \pm 2$ & $65 \pm 5$ & $-20 \pm 2$ & 327 \\
\hline
\end{tabular}

Abbreviations: TEM, transmission electron microscopy; AAS, atomic absorption spectroscopy; DLS, dynamic light scattering; MGF, mangiferin.

As shown in Figures 1, 2 and 5, the antioxidant power of mangiferin and other phytochemicals in mango peel are responsible in transforming gold salt into the corresponding AuNPs.

In order to understand the extent of loading of mangiferin onto AuNPs, which we refer as drug loading, we have performed key experiments as elaborated in numerous publications on green nanotechnology from our laboratory. ${ }^{19-21,23,26,27,35,61}$ We hypothesized that the corona around gold nanoparticles in MP-AuNPs comprises of mostly the encapsulation of mangiferin due to the large abundance of this phytochemical in the mango peel (Figure 5). Validating this hypothesis is significant in understanding drug loading of mangiferin around gold nanoparticles. In order to validate this hypothesis, we performed independent reactions of interacting mangiferin
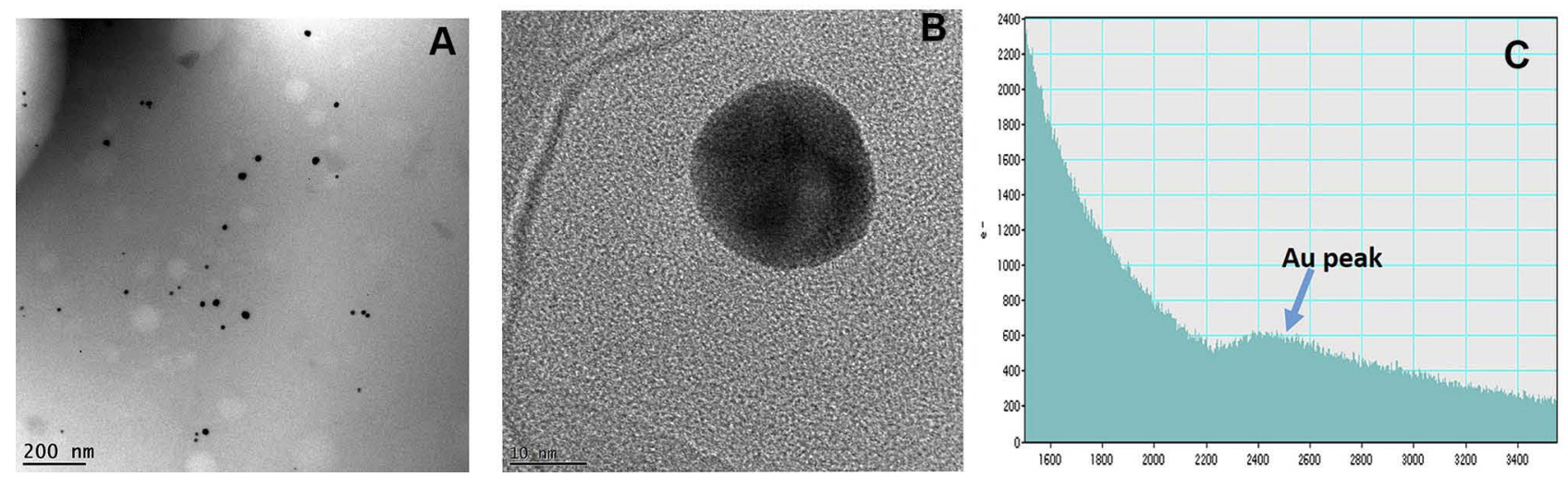

Figure 4 (A) Core size distribution of AuNPs in 'Nano Swarna Bhasma' (NSB) drug by TEM, (B) STEM image shows lattice structure of Au, (C) Graph shows presence of Au in NSB drug by EELS.
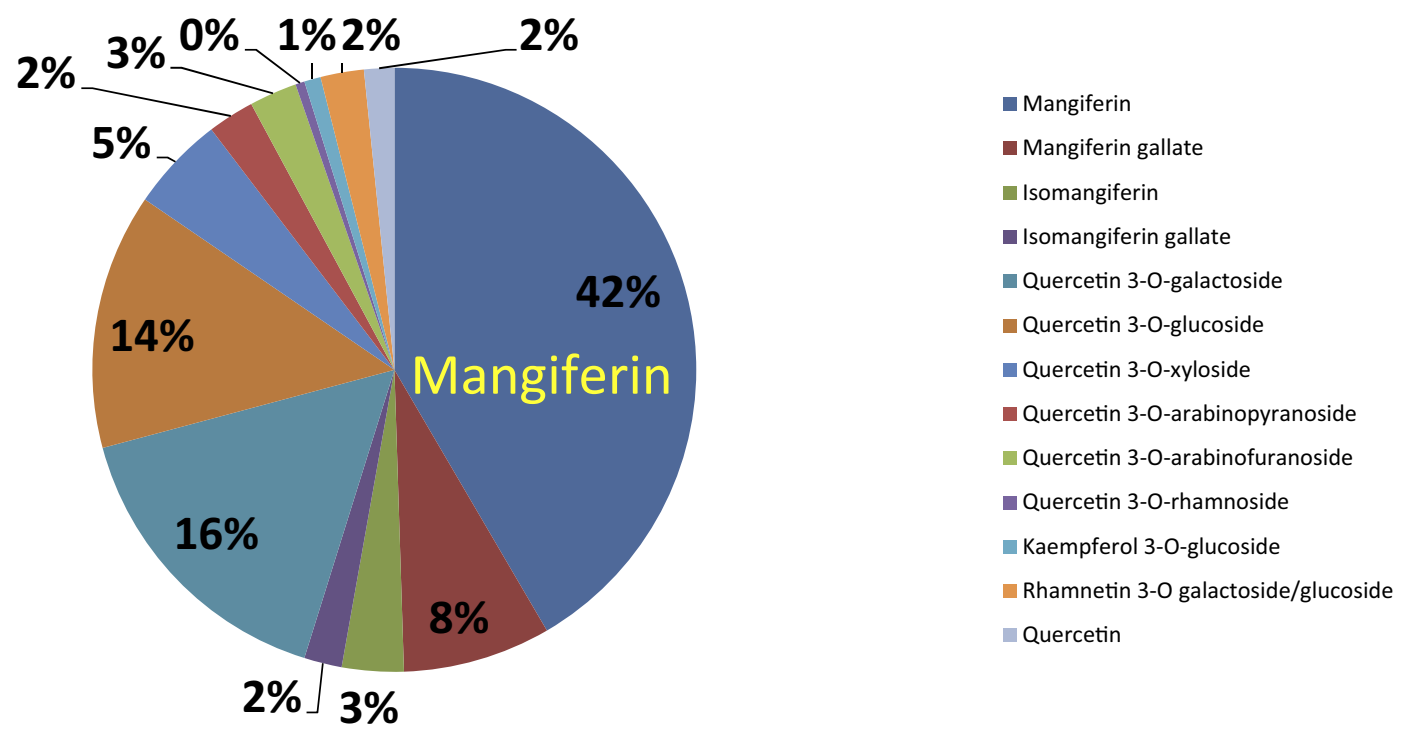

Figure 5 Pie chart represents polyphenols and various phytochemical compounds in mango peel $(\mathrm{mg} / \mathrm{Kg})$ on dry matter basis. 
with gold salt (Figure 2). Complete physicochemical characteristics of these nanoparticles, in terms of size and charge, are summarized in Table 1. We further calculated the number of mangiferin molecules per gold nanoparticle using the following equations:

\section{Calculation of Average Number of Gold Atoms per Nanoparticle}

The average number of gold atoms per nanoparticle is calculated using core size value of the MP-AuNPs and MGF-AuNPs obtained from TEM analyses. The average core diameter of the particles $(D, \mathrm{~nm})$ are summarized in Table 1. We found that the core sizes of MP-AuNPs and MGF-AuNPs were similar. Assuming a spherical shape and a uniform face-centered cubic $(f c c)$ structure, the average number of gold atoms $(N)$ for each nano-sphere was calculated using Eq. 1, where $\rho$ is the density of the $f c c$ gold $\left(19.3 \mathrm{~g} / \mathrm{cm}^{3}\right)$ and $M$ is the atomic weight of gold (197 $\mathrm{g} / \mathrm{mol})$ and $N_{A}$ is the Avogadro's number. ${ }^{62}$

$$
N=\frac{\pi \rho D^{3}}{6 M} N_{A}
$$

$N=1.3 \times 10^{6}$ gold atoms per nanoparticle

The calculations as outlined above confirmed that MPAuNPs and MGF-AuNPs consisted of $1.3 \times 10^{6}$ gold atoms per nanoparticle.

\section{Determination of Concentrations of Nanoparticle Solution}

The concentration of the nanoparticle solution was calculated based on the amount of $\mathrm{NaAuCl}_{4}(100 \mu \mathrm{L}$ of $0.1 \mathrm{M})$ used for the respective nanoparticle synthesis. It involves $1 \times 10^{5}$ moles of gold or $6.0 \times 10^{18}$ total gold atoms $\left(\mathrm{N}_{\mathrm{T}}\right)$. The concentration of the nanoparticles $C$ was calculated using Eq. 2 by dividing the total number of gold atoms $\left(\mathrm{N}_{\mathrm{T}}\right)$ with the average number of gold atoms per nanosphere $\left(N=1.3 \times 10^{6}\right)$ and $\mathrm{V}(6 \mathrm{~mL})$ the volume of the reaction solution. ${ }^{62}$

$$
C=\frac{\mathrm{N}_{\mathrm{T}}}{N V}
$$

$=7.6 \times 10^{11}$ nanoparticles $/ \mathrm{mL}$

Determination of Number of MGF per MGF-AuNP The concentration of MGF in MGF-AuNPs is $173 \mu \mathrm{g} / \mathrm{mL}$ as obtained from LC-MS spectrophotometry. Therefore, the number of MGF molecules per $\mathrm{mL}$ is $2.5 \times 10^{17}$. Further, the number of MGF molecules per nanoparticle was calculated using the formula:
MGF per nanoparticle $=$ Number of MGF per $\mathrm{mL} /$ number of nanoparticle per $\mathrm{mL}$

$=2.5 \times 10^{17} / 7.6 \times 10^{11}=3.3 \times 10^{5}$

\section{Determination of Number of MGF per MP-AuNP}

The concentration of MGF in MP-AuNPs is $9 \mu \mathrm{g} / \mathrm{mL}$ as obtained from LC-MS spectrophotometry. Therefore, the number of MGF moles per $\mathrm{mL}$ is $1.2 \times 10^{16}$. Further, the number of MGF molecules per NPs was calculated using the formula:

MGF per nanoparticle $=$ Number of MGF per mL/ number of NPs per $\mathrm{mL}$

$=1.2 \times 10^{16} / 7.6 \times 10^{11}=1.7 \times 10^{4}$

Stark similarities of physicochemical properties including plasmon resonance, core size, hydrodynamic size - of MP-AuNPs and MGF-AuNPs (Table 1) - unequivocally confirmed that the phytochemical corona constitution of these two types of nanoparticles are very similar. We have therefore reasoned that the largely abundant mangiferin phytochemical dominates in the formation of phytochemical corona and that the mango peel extracts can be reliably used to achieve effective mangiferin drug loading around gold nanoparticles. The similarity of physicochemical parameters of MGF-AuNPs and MP-AuNPs also support the hypothesis that the number of mangiferin units per nanoparticle in these two types of nanoparticles are comparable.

These drug loading experiments gave us the confidence to utilize mango peel-derived gold nanoparticles for further in vivo therapeutic efficacy studies discussed in the following sections.

\section{Effect of NSB Drug on Cancer and Normal Cell Viability}

In order to test the in vitro antitumor efficacy of the NSB drug, serial dilutions were prepared in DMEM (Dulbecco's Modified Eagle Medium) media for treatment with tumor cells. The cell viability profile of the NSB drug was evaluated against breast cancer cells (MDA-MB-231) and also with the normal endothelial cells (HAECs) using MTT assays (Figure 6). The cell viability profiles demonstrated that the NSB drug exhibited dose dependent efficacy in cell death of cancer cells. Our results also confirmed that the NSB drug is selectively toxic to tumor cells with minimal or no toxicity against the normal cells (Figure 6).

Based on these encouraging in vitro antitumor efficacy of the NSB drug, we have further performed in vivo 


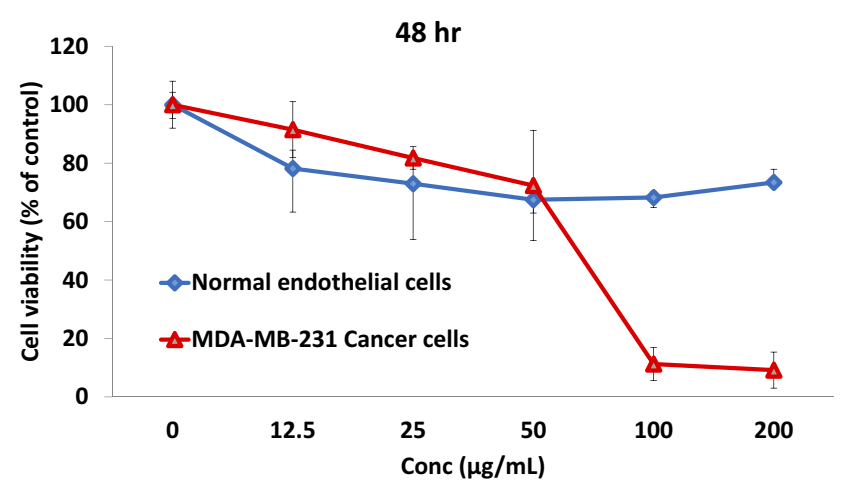

Figure 6 Effect of NSB drug on breast cancer (MDA-MB-23I) cells viability and non-toxic nature on normal endothelial (HAECs) cells.

therapeutic efficacy to investigate the ability of this new drug to control or reduce tumor size. We have used mice, implanted with breast tumor xenografts of human breast tumor cells (MDA-MB-231), in the therapeutic efficacy studies. MDA-MB-231 breast tumor cells are excellent models for testing the efficacy of new therapeutic agents for treating triple-negative breast cancers in human patients. ${ }^{63}$

\section{In vivo Therapeutic Efficacy}

The in vivo therapeutic efficacy study was conducted in three groups of mice bearing breast tumors with comparable size. The mean tumor volume of these groups ranged from 0.01 to $0.02 \mathrm{~cm}^{3}$ and group mean body weights ranged from 24 to $30 \mathrm{~g}$. The animals (group 2 and 3) were given NSB drug twice per week (in peanut butter) whereas the first group was given peanut butter without the drug which served as an untreated control group. The in vivo study was performed over a period of 8-9 weeks; the day of randomization and treatment was considered as day zero.

Results of therapeutic efficacy studies, as summarized in Figure 7, provided conclusive evidence that the NSB drug has the ability to reduce tumor volume. As outlined in Figure 7, after approximately 1 week of treatment (day 10), the tumor volume appeared to decrease in the treated group of tumors bearing mice. Four weeks post-treatment (day 24), the tumor volume of the treated group was between 0.02 $\pm 0.01-0.03 \pm 0.01 \mathrm{~cm}^{3}$ and continued to decrease significantly. Five weeks post-treatment (day 31), tumor volume of the untreated control group $\left(0.08 \pm 0.02 \mathrm{~cm}^{3}\right)$ was significantly larger than the tumor volumes of the treated groups $\left(0.03 \pm 0.01-0.04 \pm 0.01 \mathrm{~cm}^{3}\right)$ (Groups 2-3). NSB drug at the doses of 3 and $7 \mathrm{mg} / 30 \mathrm{gm}$ of animal body weight showed significant reduction in the tumor volumes.

Complete analysis of the therapeutic efficacy data has revealed that the tumor volumes for the control group remained larger than the treated groups throughout the course of therapeutic efficacy investigations. Therefore, our results demonstrate that the NSB drug has significant therapeutic efficacy as reflected in its ability to control/ reduce the tumor volumes by over $80 \%$ (during 60 days of treatment; Figure 7) as compared to the control groups.

\section{In vivo Toxicity Studies of Nano Swarna Bhasma (NSB) Drug}

The body weight of all the experimental animals was measured to evaluate the toxicity of the NSB drug. The drug was given orally twice per week for 60 days. The animals were monitored for their body weight and health

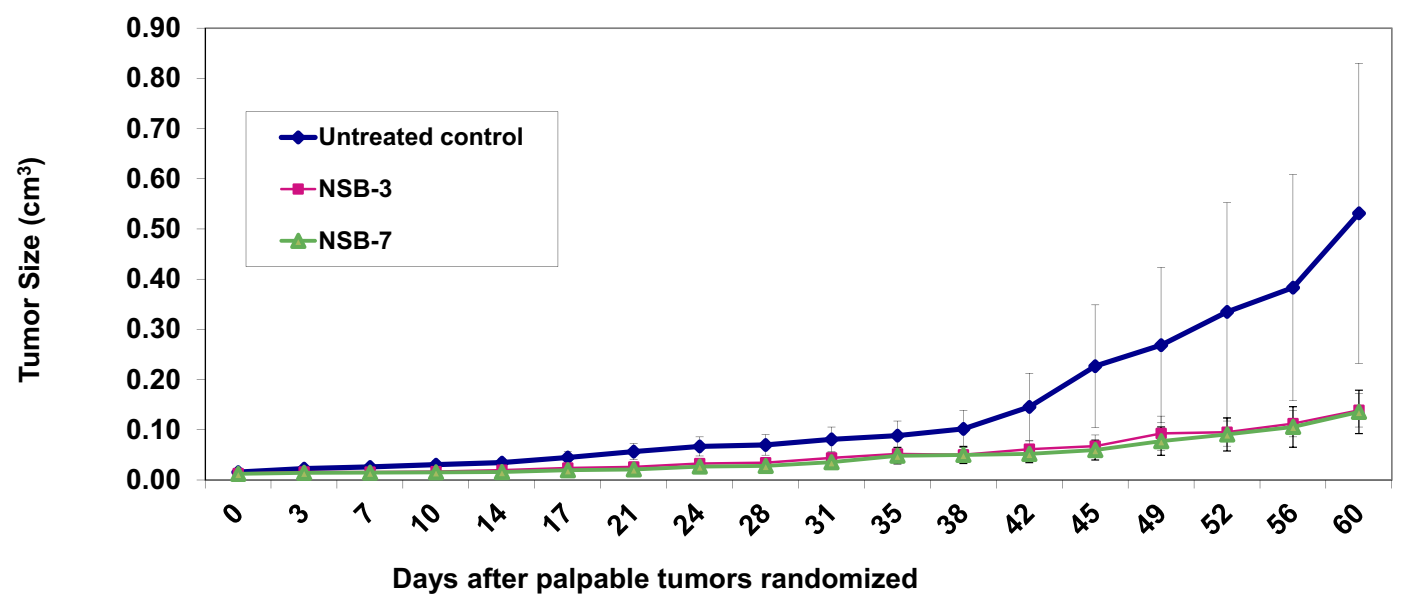

Figure 7 Therapeutic effects of NSB drug to control or reduce tumor size in human breast tumor bearing SCID female mice. Animals randomized and treated orally on day zero. Treatment was given twice per week; $n=7$.

Note: Untreated control group represents no treatment, only tumor bearing SCID mice. 
conditions during the treatment period. Body weights were measured twice per week for all the groups. Animals were sacrificed at the end of the study or when tumors reached endpoint. The body weights of NSB drug treated animals were found to be similar to that of the normal control group (Figure 8). Overall, the detailed analysis, as outlined in Figures 7 and 8, demonstrates that NSB drug did not cause any adverse systemic toxicity throughout the course of the treatment regimen.

There are no effective FDA approved drugs so far that control the growth and proliferation of triple-negative breast tumors. The results of the therapeutic efficacy studies using the NSB drug, as shown in Figure 7, are highly significant because doses in the range of 3-7 mg per 30 gm mouse, administered two times a week, are able to control the growth and proliferation in a highly effective way as compared to the untreated control groups. The breast tumor model used in our investigation is a highly aggressive tumor classified to be triple-negative . Our results, therefore, provide conclusive experimental evidence that the NSB drug can be used in humans for treating breast tumors to relieve tumor burden and to enhance the life expectancy and quality of life of patients. Therefore, regulatory permission to conduct pilot clinical trials in human breast cancer patients was sought from the Indian Ayurvedic drug regulatory agency AYUSH. Results of the pilot clinical trials are described below.

\section{Results of Pilot Clinical Trial Investigations \\ Efficacy}

Efficacy was a secondary objective of the study. Mean sum of the longest diameter of target lesion in treatment arm

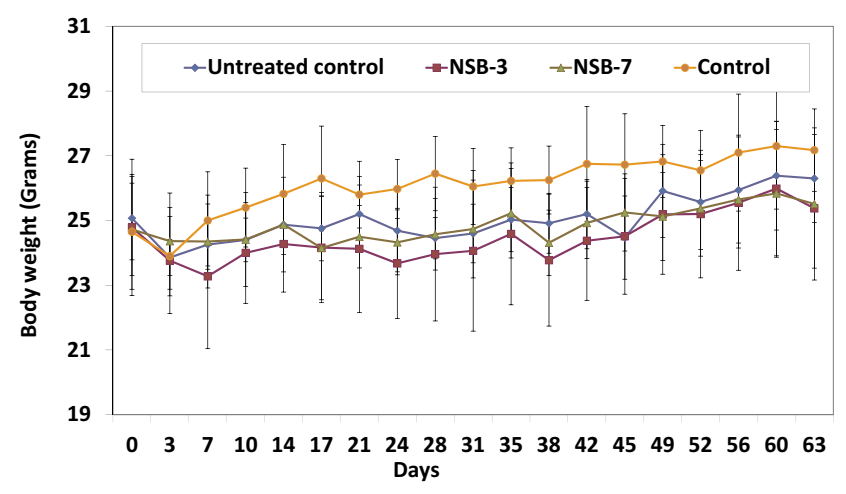

Figure 8 Effect of NSB drug on body weight of SCID mice after oral administration in human breast cancer bearing SCID mice.

Note: Untreated control group represents no treatment, only tumor bearing SCID mice, and control group represents no treatment and no tumor bearing mice (healthy control mice).
B (standard of care treatment along with the NSB drug) was reduced at week 7 and further reduced at week 12, in comparison with the baseline measurements. Whereas in the other treatment group (arm A which received Standard of Care drugs), where the patients were treated only with the "standard of care treatment", drastic increase in the mean sum of the longest diameter was observed at week 7 , which reduced at the last visit with respect to the baseline measurements. Mean SD of treatment arm B (3.31) was much higher as compared to that of treatment arm A (1.37), i.e. lesion sizes of treatment arm A were of high variability. Mean SD of treatment arm A increased to 4.41 (percent change from baseline 65.00 ) at visit 4 and 3.78 (percent change from baseline 59.64) at visit 6. On the other hand, higher mean SD of treatment arm $B$ reduced to 3.00 (percent change from baseline 18.22) at visit 4 and slightly increased to 3.64 (percent increase from baseline 28.38) at visit 6 . These observations suggest that the percent change from baseline in SD of the treatment group arm A was more than double that of the treatment arm B at the end of the treatment.

Tumor response was calculated based on RECIST 1.1 for all completed patients. There were no non-target lesions diagnosed in any of the patients. Therefore, response in target lesions corresponds to overall response. None of the patients exhibited complete response during the study. Two patients $(66.7 \%)$ in treatment arm A and one $(33.3 \%)$ in treatment arm B showed partial response at week 12 of evaluation. Two (66.7\%) patients showed no change in the lesion. i.e. stable disease in treatment arm B at week 12 evaluation. Progressive disease response was observed in one patient $(33.3 \%)$ throughout the treatment period of treatment arm A, whereas none of the patients showed progressive disease in treatment arm B.

At the end of the treatments, i.e. week 12, clinical benefit rate/disease control rate was calculated for all the patients. Patients treated with NSB drug along with the "standard of care treatment" (arm B) exhibited 100\% clinical benefit rate when compared to the treatment group arm A which received only the "Standard of Care Treatment".

\section{Safety}

Out of the total enrolled patients, two patients each from both the $\mathrm{A}$ and $\mathrm{B}$ groups experienced at least one adverse event. Majority of adverse events ( 07 AEs) were mild in severity. Only one AE reported by the patient in treatment arm B was severe in nature. More than 50\% of total reported AEs were from treatment arm A, out of which 
05 were possibly related and one each was unlikely related and unrelated to the study drug. There were 04 incidences of Neutropenia of mild severity reported by one patient from treatment arm A followed by hyperacidity and weakness generalized reported by two patients, one each from both the treatment arms. Anemia was reported for one patient from treatment arm B, severe in nature but not related to the study drug.

\section{Discussion Related to Pilot Clinical Trial Investigations}

Challenges continue in the treatment of the three most common types of breast cancer subtypes: estrogen-receptor-positive $(\mathrm{ER}+)$, human epidermal growth factor receptor 2-positive (HER2+), and the more heterogenous triple-negative breast cancer (TNBC) diseases. ${ }^{64,65}$ Treatments focused on targeting the molecular mechanisms of endocrine resistance in ER+ advanced breast cancer are evolving with some success. ${ }^{66-69}$ Although several targeted treatments including Afinitor, Avastin, Herceptin, Ibrance, Kadcyla, Kisqali, Lynparza, Nerlynx, Perjeta, Tykerb, and Verzenio - are in clinical practice for treating patients with HER2+ breast cancer, the disease continues to show considerable mortality within the patient population around the world. ${ }^{70-72}$ In particular, the targeted agents have had much less effect in patients with triplenegative breast cancer. Poly ADP ribose polymerase (PARP) inhibitors are currently the most promising agents in this group, based on the similarity of this subtype to ovarian cancers. ${ }^{73-77}$ Alternative holistic approaches are being continuously sought as the World Health Organization (WHO) forecasts that approximately $80 \%$ of the global population would use one or the other form of alternative medicine in their life time. ${ }^{78}$

In this report, we have described the application of green nanotechnology to holistic Ayurvedic medicine. Our discovery of Nano Swarna Bhasma (DNANOSTANNA capsules) through green nanotechnology as outlined in Figure 1, 2 and Scheme 1 is one such formulation containing gold nanoparticles encapsulated, with a cocktail of phytochemicals of gooseberry, mango, turmeric and gum arabic - all approved for use in the Ayurvedic medicine modality. The compelling in vitro antitumor results and the in vivo therapeutic efficacy of the NSB drug prompted us to obtain regulatory approval from the Indian Ayurvedic medicine AYUSH regulatory authority to initiate pilot clinical trials in human breast cancer patients.

In this open label, controlled study, "Standard of Care Treatment" was compared with the same treatment combined with herbal formulation NSB drug in breast cancer. Seven female patients with pathologically confirmed invasive breast carcinoma stage IIIA or IIIB were enrolled in the study. One patient was withdrawn at baseline visit due to noncompliance. Out of the remaining six patients, three patients were treated with treatment $\mathrm{A}$ and three were treated with treatment $\mathrm{B}$. All six patients completed the study and received full dose of treatment in both groups A and B as per randomization. Safety was the primary objective of the study. Safety analysis was done on safety population. There were no alarming toxicity effects observed in both the groups.

Tumor response was calculated for patients who completed clinical trials. There were no non-target lesions diagnosed in any of the patients. Therefore, response in target lesions corresponds to overall response. None of the patients exhibited complete response during the study. Two patients $(66.7 \%)$ in treatment arm $\mathrm{A}$ and one $(33.3 \%)$ in treatment arm B showed partial response. Two (66.7\%) patients showed no change in the lesion. i.e. stable disease in treatment arm B. Progressive disease response was observed in one patient $(33.3 \%)$ of treatment arm A. None of the patients in treatment arm B showed progressive disease.

Figure 9 is a waterfall plot that presents each individual patient's response to the drug based on parameters, such as lesion size (sum of longest diameter) and its change from the baseline. One patient in treatment arm A is a nonresponder whereas all three patients in treatment arm B are responders. This means that all the patients treated with treatment arm B showed 100\% disease control rate (DCR) or clinical benefit rate $(\mathrm{CBR})$. Patients treated with treatment arm A showed 66.7\% CBR (Table 2).

Efficacy analysis was done on FAS population. At the end of 12 weeks, none of the patients showed complete response. No patient treated with NSB drug (DNANOSTANNA) capsules showed progressive disease. Patients from this group exhibited $100 \%$ clinical benefit rate.

\section{Conclusions}

Overall, we have been able to clinically translate the findings from the pre-clinical investigations of the Nano-Ayurvedic medicine gold nanoparticles-based drug to demonstrate acceptable safety and excellent efficacy results in human breast cancer patients. Administering the Nano Swarna Bhasma ( NSB) drug (DNANOSTANNA in the form of capsules) to patients with breast cancer did not show adverse effects as monitored through both vital signs and laboratory chemistries. Commonly reported adverse events were transient implying acceptable safety. Toxicity/adverse event assessment by NCI 


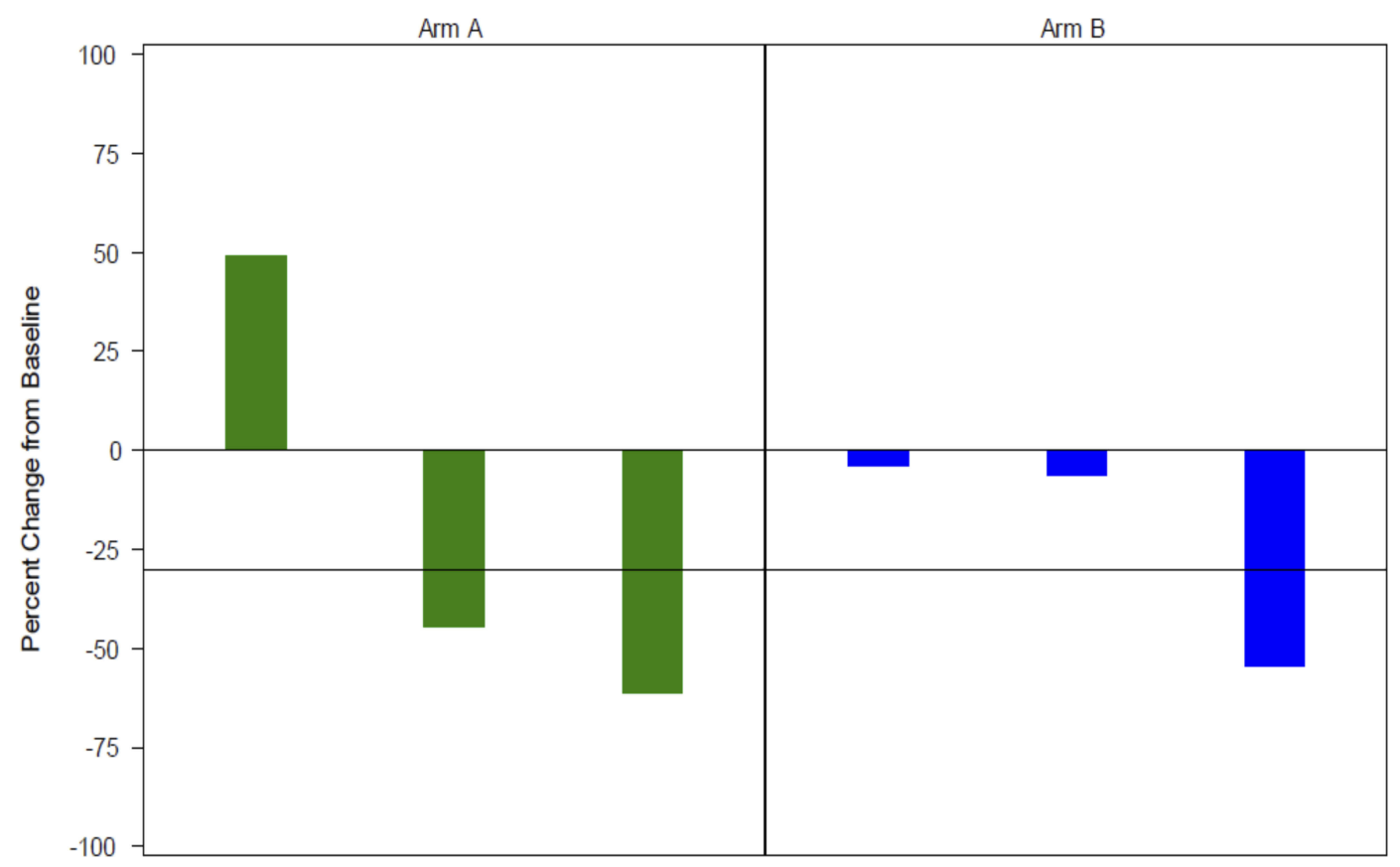

Figure 9 Waterfall plot for percent change from baseline in tumor's sum of longest diameter at week 12 by treatment.

Notes: Patients in treatment arm A received the following- Doxorubicin (60 mg/m $\mathrm{m}^{2}$ every 3 weeks as a I hr intravenous infusion) and Cyclophosphamide $\left(600 \mathrm{mg} / \mathrm{m}^{2}\right.$ every 3 weeks as a I hr intravenous infusion). Patients in treatment arm B received the following- Doxorubicin $\left(60 \mathrm{mg} / \mathrm{m}^{2}\right.$ every $3 \mathrm{weeks}$ as a $\mathrm{I}$ hr intravenous infusion), Cyclophosphamide $\left(600 \mathrm{mg} / \mathrm{m}^{2}\right.$ every 3 weeks as a I hr intravenous infusion) and NSB Drug- two capsules thrice a day after food.

toxicity criteria performed at every visit certainly provided clinical evidence on the potential of this therapy containing Nano Swarna Bhasma-gold nanoparticles encapsulated with a proprietary combination of various Ayurvedic herbs (Scheme 1). Our results also indicate that Nano Swarna

Table 2 Summary of Overall, Target and Non-Target Lesion Response at Week 12 by Treatment

\begin{tabular}{|l|l|l|l|}
\hline Tumor response & $\begin{array}{l}\text { Arm } \\
\text { A (N=3) } \\
\text { n (\%) }\end{array}$ & $\begin{array}{l}\text { Arm } \\
\text { B (N=3) } \\
\mathbf{n}(\%)\end{array}$ & $\begin{array}{l}\text { Total } \\
\mathbf{( N = 6 )} \\
\mathbf{n}(\%)\end{array}$ \\
\hline Overall response
\end{tabular}

Bhasma can be safely used as a valuable adjuvant therapeutic agent to reduce the adverse effects of routine chemotherapeutic agents while providing measurable therapeutic efficacy in treating breast and other forms of human cancers. Green nanotechnology-based Nano-Ayurvedic formulations, such as NSB drug, show minimal toxicity to normal cells and tissues. Therefore, Nano-Ayurvedic medicine modalities present realistic opportunities as holistic and highly effective interventions in the care and treatment of cancer patients globally.

\section{Ethics Approval and Informed Consent}

This study, including the procedures for patient enrollment and recruitment, was approved by the Institutional Review Board of two independent hospitals (Ashwin Hospital, Chennai, India and Erode Cancer Institute, Erode, India). All patients, who participated in the study provided written informed consent. This study was conducted in accordance with the approved guidelines of the government of India regulatory authority of Ayurveda, Yoga and Naturopathy, Unani, Siddha and Homoeopathy (abbreviated as AYUSH). This study was conducted in accordance with the ethical principles laid down by Declaration of Helsinki (Taipei 2016) following the principles of ICH Guidelines for Good Clinical Practice (1997) and Schedule. 


\section{Acknowledgments}

Kattesh V Katti thanks the Medical School and the Institute of Green Nanotechnology of the University of Missouri, for providing logistical resources for various in vitro and in vivo investigations outlined in this paper. Funds from Dhanvantari Nano Ayushadi (DNA) for sponsoring the in vitro and in vivo investigations are gratefully acknowledged. We also acknowledge the support of the contract research organization, 15 Clinical Research, Pvt. Ltd, Chennai, India, for conducting the pilot clinical trials.

\section{Disclosure}

Menka Khoobchandani, Alice Raphael Karikachery, Velaphi C. Thipe, and Chintamani M Joshi report grants from DNA Pvt Ltd India and University of Missouri, during the conduct of this study. The authors report no other conflicts of interest in this work.

\section{References}

1. Peterson CT, Denniston K, Chopra D. Therapeutic uses of Triphala in ayurvedic medicine. J Altern Complement Med. 2017;23(8):607-614. doi:10.1089/acm.2017.0083

2. Rao GH. Opportunities and challenges in Ayurveda: global perspective. Altern Integr Med. 2017;6(2):239.

3. Sharma R, Kuca K, Nepovimova E, Kabra A, Rao MM, Prajapati PK. Traditional Ayurvedic and herbal remedies for Alzheimer's disease: from bench to bedside. Expert Rev Neurother. 2019;19:359-374. doi:10.1080/14737175.2019.1596803

4. Rioux J, Howerter A. Outcomes from a whole-systems Ayurvedic medicine and Yoga therapy treatment for obesity pilot study. $J$ Altern Complement Med. 2019;25:S124-S137. doi:10.1089/acm.2018.0448

5. Barnes PMBB, Nahin R Complementary and alternative medicine use among adults and children: United States, 2007. 2008.

6. Chopra A, Doiphode VV. Ayurvedic medicine. Core concept, therapeutic principles, and current relevance. Med Clin North Am. 2002;86(1):75-89, vii. doi:10.1016/S0025-7125(03)00073-7

7. Conboy L, Edshteyn I, Garivaltis H. Ayurveda and Panchakarma: measuring the effects of a holistic health intervention. ScientificWorldJournal. 2009;9:272-280. doi:10.1100/tsw.2009.35

8. Gogtay NJ, Bhatt HA, Dalvi SS, Kshirsagar NA. The use and safety of non-allopathic Indian medicines. Drug Saf. 2002;25 (14):1005-1019. doi:10.2165/00002018-200225140-00003

9. Chopra A, Saluja M, Tillu G, et al. Ayurvedic medicine offers a good alternative to glucosamine and celecoxib in the treatment of symptomatic knee osteoarthritis: a randomized, double-blind, controlled equivalence drug trial. Rheumatology (Oxford). 2013;52 (8):1408-1417. doi:10.1093/rheumatology/kes414

10. Clarke TCBL, Stussman BJ, Barnes PM, Nahin RL. Trends in the use of complementary health approaches among adults: United States, 2002-2012. Natl Health Stat Report. 2015;10(79):1-16.

11. Buckner CA, Lafrenie RM, Denommee JA, Caswell RJM, Want DA. Complementary and alternative medicine use in patients before and after a cancer diagnosis. Curr Oncol. 2018;25(4):. doi:10.3747/co.25.3884.

12. Shankar D. Directions for revitalization of Ayurveda in the $21 \mathrm{st}$ century. J Ayurveda Integr Me. 2018;9(4):245-247. doi:10.1016/j. jaim.2018.12.002

13. Jin X, Ruiz B, Sze DM, Chan GC, Cochrane Database Syst Rev. 2012;13(6):1-37. doi:10.1002/14651858
14. Risberg T, Kolstad A, Bremnes Y, et al. Knowledge of and attitudes toward complementary and alternative therapies; a national multicentre study of oncology professionals in Norway. Eur J Cancer. 2004;40(4):529-535. doi:10.1016/j.ejca.2003.11.011

15. Cassileth BR, Deng G. Complementary and alternative therapies for cancer. Oncologist. 2004;9(1):80-89. doi:10.1634/theoncologist. 9-1-80

16. Kumar S, Dobos GJ, Rampp T. The significance of Ayurvedic medicinal plants. J Evid Based Complementary Altern Med. 2017;22 (3):494-501. doi:10.1177/2156587216671392

17. Tandon N, Yadav SS. Contributions of Indian Council of Medical Research (ICMR) in the area of Medicinal plants/Traditional medicine. J Ethnopharmacol. 2017;197:39-45. doi:10.1016/j.jep.2016.07.064

18. Pandey S, Walpole C, Shaw PN, Cabot PJ, Hewavitharana AK, Batra J. Bio-guided fractionation of papaya leaf juice for delineating the components responsible for the selective anti-proliferative effects on prostate cancer cells. Front Pharmacol. 2018;9:1319. doi:10.3389/ fphar.2018.01319

19. Khoobchandani M, Zambre A, Katti K, Lin CH, Katti VK. Green nanotechnology from brassicaceae: development of broccoli phytochemicals-encapsulated gold nanoparticles and their applications in nanomedicine. Int $J$ Green Nanotechnol. 2013;4 (9): 1425-1436.

20. Nune SK, Chanda N, Shukla R, et al. Green nanotechnology from tea: phytochemicals in tea as building blocks for production of biocompatible gold nanoparticles. J Mater Chem. 2009;19(19):2912-2920. doi:10.1039/b822015h

21. Khoobchandani M, Katti K, Maxwell A, Fay WP, Katti KV. Laminin receptor-avid nanotherapeutic EGCg-AuNPs as a potential alternative therapeutic approach to prevent restenosis. Int J Mol Sci. 2016;17 (3):316. doi:10.3390/ijms17030316

22. Shukla R, Nune SK, Chanda N, et al. Soybeans as a phytochemical reservoir for the production and stabilization of biocompatible gold nanoparticles. Small. 2008;4(9):1425-1436. doi:10.1002/smll.v4:9

23. Khoobchandani M, Katti K, Karikachery RA, Thipe CV, Bloebaum LRP, Katti VK. Targeted phytochemical-conjugated gold nanoparticles in cancer treatment. In: Saxena MKA, editor Biotechnology Products in Everyday Life. New York: Springer International Publishing; 2018: 37-52.

24. Katti KV, Khoobchandani M, Thipe VC, et al. Prostate tumor therapy advances in nuclear medicine: green nanotechnology toward the design of tumor specific radioactive gold nanoparticles. $J$ Radioanal Nucl Ch. 2018;318(3):1737-1747.

25. Thipe VC, Keyster M, Katti KV. Sustainable nanotechnology: mycotoxin detection and protection. Nanotech Life Sci. 2018;323-349.

26. Katti K, Chanda N, Shukla R, et al. Green nanotechnology from cumin phytochemicals: generation of biocompatible gold nanoparticles. Int J Green Nanotechnol Biomed. 2009;1(1):B39B52. doi:10.1080/19430850902931599

27. Al-Yasiri AY, Khoobchandani M, Cutler CS, et al. Mangiferin functionalized radioactive gold nanoparticles (MGF-(198)AuNPs) in prostate tumor therapy: green nanotechnology for production, in vivo tumor retention and evaluation of therapeutic efficacy. Dalton T. 2017;46(42):14561-14571. doi:10.1039/C7DT00383H

28. Chanda N, Kan P, Watkinson LD, et al. Radioactive gold nanoparticles in cancer therapy: therapeutic efficacy studies of GA-198AuNP nanoconstruct in prostate tumor-bearing mice. Nanomedicine. 2010;6 (2):201-209. doi:10.1016/j.nano.2009.11.001

29. Chanda N, Kattumuri V, Shukla R, et al. Bombesin functionalized gold nanoparticles show in vitro and in vivo cancer receptor specificity. Proc Natl Acad Sci U S A. 2010;107(19):8760-8765. doi:10.1073/pnas.1002143107

30. Fent GM, Kim CS, Kannan DY, Katti K, Chanda N, Katti K. Biodistribution of maltose and gum arabic hybrid gold nanoparticles after intravenous injection in juvenile swine. Nanomedicine. 2009;5 (2):128-135. doi:10.1016/j.nano.2009.01.007 
31. Kattumuri V, Katti K, Bhaskaran S, et al. Gum arabic as a phytochemical construct for the stabilization of gold nanoparticles: in vivo pharmacokinetics and X-ray-contrast-imaging studies. Small. 2007;3(2):333-341. doi:10.1002/(ISSN)1613-6829

32. Shukla R, Chanda N, Zambre A, et al. Laminin receptor specific therapeutic gold nanoparticles (198AuNP-EGCg) show efficacy in treating prostate cancer. Proc Natl Acad Sci U S A. 2012;109 (31):12426-12431. doi:10.1073/pnas.1121174109

33. Boote E, Fent G, Kattumuri V, et al. Gold nanoparticle contrast in a phantom and juvenile swine: models for molecular imaging of human organs using X-ray computed tomography. Acad Radiol. 2010;17(4):410-417. doi:10.1016/j.acra.2010.01.006

34. Chanda N, Shukla R, Katti KV, Kannan R. Gastrin releasing protein receptor specific gold nanorods: breast and prostate tumor avid nanovectors for molecular imaging. Nano Lett. 2009;9(5):1798-1805. doi: $10.1021 / \mathrm{n} 18037147$

35. Chanda N, Shukla R, Zambre A, et al. An effective strategy for the synthesis of biocompatible gold nanoparticles using cinnamon phytochemicals for phantom CT imaging and photoacoustic detection of cancerous cells. Pharm Res. 2011;28(2):279-291. doi:10.1007/s11095-0100276-6

36. Berning DE, Charles KVK, Barnes L, Volkert WA. Chemical and biomedical motifs of the reactions of hydroxymethylphosphines with amines, amino acids, and model peptides. J Am Chem Soc. 1999;121 (8):1658-1664. doi:10.1021/ja9827604

37. Gamal-Eldeen AM, Moustafa D, El-Daly SM, et al. Gum Arabic-encapsulated gold nanoparticles for a non-invasive photothermal ablation of lung tumor in mice. Biomed Pharmacother. 2017;89:1045-1054. doi:10.1016/j.biopha.2017.03.006

38. Gamal-Eldeen AM, Moustafa D, El-Daly SM, et al. Photothermal therapy mediated by gum Arabic-conjugated gold nanoparticles suppresses liver preneoplastic lesions in mice. J Photochem Photobiol B. 2016;163:47-56. doi:10.1016/j.jphotobiol.2016.08.009

39. Gamal-Eldeen AM, Moustafa D, El-Daly SM, Katti KV. Efficacy of Gum Arabic-conjugated gold nanoparticles as a photothermal therapy for lung cancer: in vitro and in vivo approaches. Eur $J$ Cancer. 2014;50:E46-E46. doi:10.1016/j.ejca.2014.03.175

40. Kannan R, Rahing V, Cutler C, et al. Nanocompatible chemistry toward fabrication of target-specific gold nanoparticles. J Am Chem Soc. 2006;128(35):11342-11343. doi:10.1021/ja063280c

41. Kannan R, Zambre A, Chanda N, et al. Functionalized radioactive gold nanoparticles in tumor therapy. Wiley Interdiscip Rev Nanomed Nanobiotechnol. 2012;4(1):42-51. doi:10.1002/wnan.161

42. Katti VK, Kannan R, Katti KK, et al., Inventor. EGCG stabilized gold nanoparticles, therapies and sensing. 2016.

43. Katti KK, Kattumuri V, Bhaskaran S, Katti KV, Kannan R. Facile and general method for synthesis of sugar coated gold nanoparticles. Int J Green Nanotechnol Biomed. 2009;1(1):B53-B59. doi:10.1080/ 19430850902983848

44. Kothari KK, Gali H, Prabhu KR, et al. Synthesis and characterization of $(99 \mathrm{~m}) \mathrm{Tc}-$ and (188)Re-complexes with a diamidodihydroxymethylenephosphine-based bifunctional chelating agent (N(2)P(2)-BFCA). Nucl Med Biol. 2002;29(1):83-89. doi:10.1016/ S0969-8051(01)00280-3

45. McLaughlin M, Chanda N, Lever JR, et al. Evaluation of receptor affinity of Au-198-starch-nanoparticles conjugated to bombesin. J Labelled Compd Rad. 2011;54:S549-S549.

46. Sinha S, McKnight D, Katti VK, et al. Gold nanoparticles stabilized in gum arabic for corneal gene therapy. Invest Ophthalmol Vis Sci. 2008;49:4787.

47. Shukla R, Zambre A, Chanda N, et al. Clinical translation of radioactive gold nanoparticle-based nanoceutical (EGCG-(AuNP)-Au-198) for prostate tumor therapy. J Labelled Compd Rad. 2011;54:S89-S89.
48. Kattumuri VCM, Guha S, Raghuraman K, Katti VK, Ghosh K, Patel RJ. Agarose-stabilized gold nanoparticles for surface-enhanced Raman spectroscopic detection of DNA nucleosides. Appl Phys Lett. 2006;153114:88.

49. Thipe CV, K M, Katti VK. Sustainable nanotechnology: mycotoxin detection and protection. In: Abd-Elsalam KA, editor RP. Nanobiotechnology Applications in Plant Protection. Springer; 2018.323-349.

50. Das S, Das MC, Paul R. Swarna Bhasma in cancer: a prospective clinical study. Ayu. 2012;33(3):365-367. doi:10.4103/0974-8520.108823

51. Beaudet D, Badilescu S, Kuruvinashetti K, et al. Comparative study on cellular entry of incinerated ancient gold particles (Swarna Bhasma) and chemically synthesized gold particles. Sci Rep. 2017;7 (1):10678. doi:10.1038/s41598-017-10872-3

52. Pal D, Sahu CK, Haldar A. Bhasma: the ancient Indian nanomedicine. J Adv Pharm Technol Res. 2014;5(1):4-12. doi:10.4103/2231-4040. 126980

53. Paul W, Sharma CP. Blood compatibility studies of Swarna bhasma (gold bhasma), an Ayurvedic drug. Int J Ayurveda Res. 2011;2 (1):14-22. doi:10.4103/0974-7788.83183

54. Visintine JA. NANO AYURVEDIC MEDICINE - Trademark Details. Vol. 87509219. USA:The Curators of the University of Missouri; 2017. Available from: https://trademarks.justia.com/875/09/nanoayurvedic-87509219.html. Accessed December 24, 2019.

55. Koyanagi M, Kawakabe S, Arimura Y. A comparative study of colorimetric cell proliferation assays in immune cells. Cytotechnology. 2016;68(4):1489-1498. doi:10.1007/s10616-015-9909-2

56. Barreto JC, Trevisan MT, Hull WE, et al. Characterization and quantitation of polyphenolic compounds in bark, kernel, leaves, and peel of mango (Mangifera indica L.). J Agric Food Chem. 2008;56 (14):5599-5610. doi:10.1021/jf800738r

57. Joubert E, Manley M, Botha M. Use of NIRS for quantification of mangiferin and hesperidin contents of dried green honeybush (Cyclopia genistoides) plant material. J Agric Food Chem. 2006;54 (15):5279-5283. doi:10.1021/jf0606171

58. Masibo M, He Q. Major mango polyphenols and their potential significance to human health. Compr Rev Food Sci F. 2008;7 (4):309-319. doi:10.1111/crfs.2008.7.issue-4

59. Ribeiro SMR, Barbosa LCA, Queiroz JH, Knodler M, Schieber A. Phenolic compounds and antioxidant capacity of Brazilian mango (Mangifera indica L.) varieties. Food Chem. 2008;110(3):620-626.

60. Takeda T, Tsubaki M, Kino T, et al. Mangiferin enhances the sensitivity of human multiple myeloma cells to anticancer drugs through suppression of the nuclear factor kappa B pathway. Int $J$ Oncol. 2016;48(6):2704-2712. doi:10.3892/ijo.2016.3470

61. Thipe VC, Panjtan Amiri K, Bloebaum P, et al. Development of resveratrol-conjugated gold nanoparticles: interrelationship of increased resveratrol corona on anti-tumor efficacy against breast, pancreatic and prostate cancers. Int J Nanomedicine. 2019;14:4413-4428. doi:10.2147/ IJN.S204443

62. Liu X, Atwater M, Wang J, Huo Q. Extinction coefficient of gold nanoparticles with different sizes and different capping ligands. Colloids Surf B Biointerfaces. 2007;58(1):3-7. doi:10.1016/j. colsurfb.2006.08.005

63. Chavez KJ, Garimella SV, Lipkowitz S. Triple negative breast cancer cell lines: one tool in the search for better treatment of triple negative breast cancer. Breast Dis. 2010;32(1-2):35-48. doi:10.3233/BD2010-0307

64. Orimo A, Gupta PB, Sgroi DC, et al. Stromal fibroblasts present in invasive human breast carcinomas promote tumor growth and angiogenesis through elevated SDF-1/CXCL12 secretion. Cell. 2005;121 (3):335-348. doi:10.1016/j.cell.2005.02.034

65. Silzle T, Kreutz M, Dobler MA, Brockhoff G, Knuechel R, KunzSchughart LA. Tumor-associated fibroblasts recruit blood monocytes into tumor tissue. Eur J Immunol. 2003;33(5):1311-1320. doi:10.1002/ eji.200323057 
66. Selli C, Dixon JM, Sims AH. Accurate prediction of response to endocrine therapy in breast cancer patients: current and future biomarkers. Breast Cancer Res. 2016;18.

67. AlFakeeh A, Brezden-Masley C. Overcoming endocrine resistance in hormone receptor-positive breast cancer. Curr Oncol. 2018;25(Suppl 1):S18-S27. doi:10.3747/co.25.3752

68. Brufsky AM. Long-term management of patients with hormone receptor-positive metastatic breast cancer: concepts for sequential and combination endocrine-based therapies. Cancer Treat Rev. 2017;59:22-32. doi:10.1016/j.ctrv.2017.06.004

69. Nasrazadani A, Thomas RA, Oesterreich S, Lee AV. Precision medicine in hormone receptor-positive breast cancer. Front Oncol. 2018;8:144. doi:10.3389/fonc.2018.00144

70. Daniels B, Kiely BE, Lord SJ, et al. Long-term survival in trastuzumabtreated patients with HER2-positive metastatic breast cancer: real-world outcomes and treatment patterns in a whole-of-population Australian cohort (2001-2016). Breast Cancer Res Treat. 2018.

71. Colomer R, Hall P, Szkultecka-Debek M, et al. Real-world treatment in patients with HER2+ metastatic breast cancer: treatment decisions in HER2+ mBC. Breast Cancer Res Treat. 2018;168(1):197-205. doi:10.1007/s10549-017-4567-z

72. Zanotti G, Hunger M, Perkins JJ, Horblyuk R, Martin M. Treatment patterns and real world clinical outcomes in ER+/HER2post-menopausal metastatic breast cancer patients in the United States. BMC Cancer. 2017;17(1):393. doi:10.1186/s12885-017-3379-1
73. Wilkes GM. Targeted therapy: attacking cancer with molecular and immunological targeted agents. Asia Pac J Oncol Nurs. 2018;5 (2):137-155. doi:10.4103/apjon.apjon_79_17

74. Sharma P. PARP inhibitor and platinum agent in triple negative breast cancer: utilizing innovative trial design to bring together something "new" and something "old”. Chin Clin Oncol. 2017;6(1):3. doi:10.21037/cco

75. Papadimitriou M, Mountzios G, Papadimitriou CA. The role of PARP inhibition in triple-negative breast cancer: unraveling the wide spectrum of synthetic lethality. Cancer Treat Rev. 2018;67:34-44. doi:10.1016/j.ctrv.2018.04.010

76. Carey JPW, Karakas C, Bui TY, et al. Synthetic lethality of PARP inhibitors in combination with MYC blockade is independent of BRCA status in triple-negative breast cancer. Cancer Res. 2018;78 (3):742-757. doi:10.1158/0008-5472.CAN-17-1494

77. Marijon H, Lee DH, Ding Let al. Co-targeting poly(ADP-ribose) polymerase (PARP) and histone deacetylase (HDAC) in triple-negative breast cancer: higher synergism in BRCA mutated cells. Biomed Pharmacother. 2018;99:543-551. doi:10.1016/j.biopha.2018.01.045

78. Chan M. WHO traditional medicine strategy: WHO Press. 2014-2023. World Health Organization. 2013;5-70.
International Journal of Nanomedicine

\section{Publish your work in this journal}

The International Journal of Nanomedicine is an international, peerreviewed journal focusing on the application of nanotechnology in diagnostics, therapeutics, and drug delivery systems throughout the biomedical field. This journal is indexed on PubMed Central, MedLine, CAS, SciSearch ${ }^{\mathbb{R}}$, Current Contents ${ }^{\mathbb{B}} /$ Clinical Medicine,

\section{Dovepress}

Journal Citation Reports/Science Edition, EMBase, Scopus and the Elsevier Bibliographic databases. The manuscript management system is completely online and includes a very quick and fair peer-review system, which is all easy to use. Visit http://www.dovepress.com/ testimonials.php to read real quotes from published authors. 